\title{
Endodontic Management of Patient with Hemophilia
}

\author{
Rahul Ramesh Atara, Pratima Ramakrishna Shenoi, Wanmala Ramchandra Mute \\ Chetana Sachin Makade, Anup Kiran Mahajan
}

\begin{abstract}
Bleeding disorders have always been a stigma to dentists. The apparent complexities in diagnosis and handling of a bleeding problem contribute to this and force us to avoid such patients in clinical practice. Hemophilia, being the commonest bleeding disorder in the world requires special mention. This article presents a case report of successful endodontic management of patient with severe Hemophilia.
\end{abstract}

Keywords: Hemophilia, Clotting factor, Endodontic management.

How to cite this article: Atara RR, Shenoi PR, Mute WR, Makade CS, Mahajan AK. Endodontic Management of Patient with Hemophilia. Int J Prosthodont Restor Dent 2013;3(3): 101-104.

\section{Source of support: Nil}

Conflict of interest: None Declared

\section{INTRODUCTION}

Hemophilia has often been called the 'Royal disease'. Queen Victoria of England was a carrier of hemophilia gene and subsequently passed the disease on to several royal families. ${ }^{1}$ Hemophilia played an important role in Russian royal family also. Two of Queen Victoria's daughters were carriers of hemophilia and they passed the disease on the Spanish, German and Russian royal families. ${ }^{2}$ Hemophilia is an $\mathrm{X}$-linked congenital bleeding disorder with a frequency of about one in 10,000 births. ${ }^{3}$ Hemophilia A is a deficiency of factor VIII and Hemophilia B (Christmas disease) is a deficiency of factor IX. Hemophilia is considered severe when plasma activity is $<1 \mathrm{IU} / \mathrm{dl}$ (normal range 50-100 IU/ $\mathrm{dL}$ ), moderate if it ranges between 2 and $5 \mathrm{IU} / \mathrm{dL}$ and mild if it ranges between 6 and $40 \mathrm{IU} / \mathrm{dL} .{ }^{4}$

Fear of bleeding during dental treatment by both patients and dentists has been the primary reason for lack of good dental care for hemophiliac patients. Bleeding disorders have been of much concern to health professionals including Dentists for quite some time. Hemophilia patients are special patients from a dental point of view, as the highly vascular oral cavity is definitely a hotspot for hemorrhage in this group of patients. It is not infrequently that a dentist becomes the first person to diagnose a bleeding disorder while performing routine dental treatments. Thorough knowledge of systematic approach is mandatory for any dental health professional raring to handle hemophiliacs the absence of which can lead to disastrous outcomes. The purpose of this article was to report a known case of severe hemophilic patient and its successful endodontic management of mandibular molar.

\section{CASE REPORT}

A 17 years old male patient with known case of hemophilia hospitalized in the medical college and reported to the department of conservative dentistry and endodontics with chief compliant of intermittent pain and swelling in lower right back region of jaw since 3 days, for which he was kept under medication (combination of ofloxacin and oronidazole with acetaminophen).

On intraoral examination intraoral sinus seen between 46 and 47. Tooth colored class I restoration was seen with 46 (Fig. 1). On vertical percussion, tenderness was positive and on horizontal percussion tenderness was negative with 46 . Electric pulp test (PARKELL, NY11735) and thermal pulp tests (heat and cold) were performed to test pulp vitality with 46 which showed no response, indicating nonvital pulp. Depending on clinical examination a provisional diagnosis of chronic periapical infection with chronic irreversible pulpitis with 46 was made.

On radiovisiographic examination radiopaque restoration seen with 46. A radiolucency below the radiopaque restoration seen which was approaching to the pulp. There was diffuse periapical radiolucency seen with mesial and distal root of 46 (Fig. 2). A final diagnosis of chronic periapical abscess with chronic irreversible pulpitis with 46 was made and nonsurgical endodontic treatment was planned with 46.

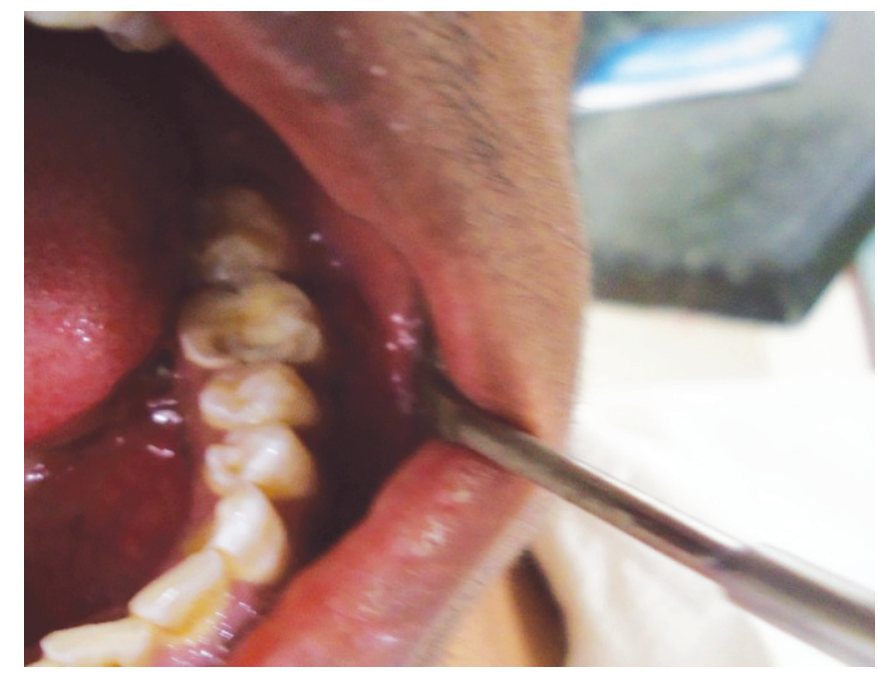

Fig. 1: Preoperative view 
Before starting for dental treatment, case was discussed with his concerned physicians and medical consent for root canal treatment was taken from them. Patient was given factor VIII intravenously a few hours before the treatment to minimize the chances of postoperative bleeding.

As tooth was nonvital root canal opening was done without administration of local anesthesia. Tooth was isolated using Rubber dam to minimize risk of traumatizing adjacent as well as intraoral tissue. Notches were placed in buccal and lingual surfaces, just above the cementoenamel junction of 46 with a fissure bur to avoid displacement of clamp. (W7) Working length was determined using apex locater (E- Magic Finder, S-Denti Co., Ltd) and radiovisiography (Kodak) (Fig. 3). Canals were irrigated with $5 \%$ sodium hypochlorite (Septodont) and normal saline and closed intracanal calcium hydroxide ( $\mathrm{RC}$ Cal) was given to the patient. Patient was prescribed with suitable antibiotic (combination of ofloxacin and oronidazole) and acetaminophen twice in a day for 3 days $\mathrm{BD}$ and chlorhexidine mouth rinse to reduce microbial flora during appointments.

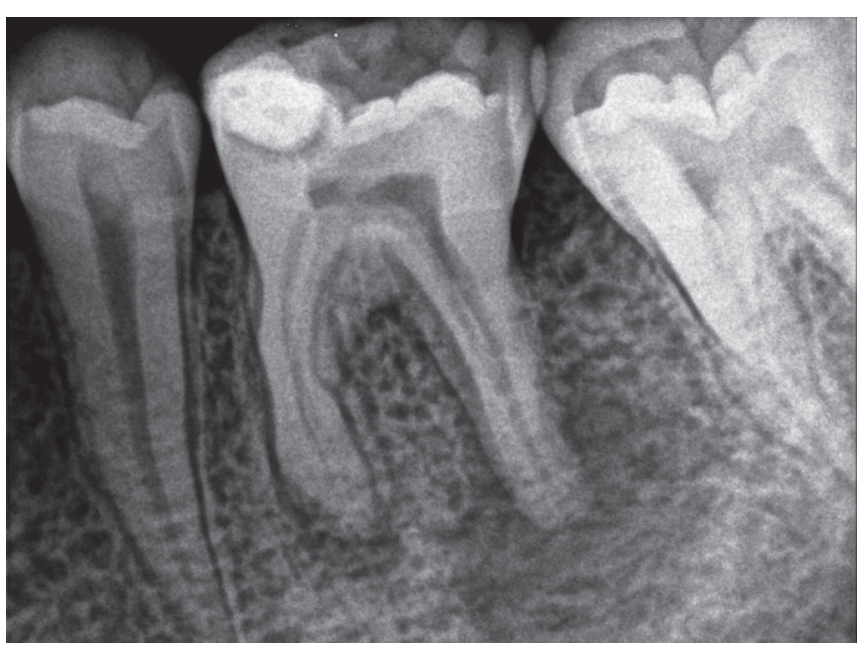

Fig. 2: Preoperative lopa

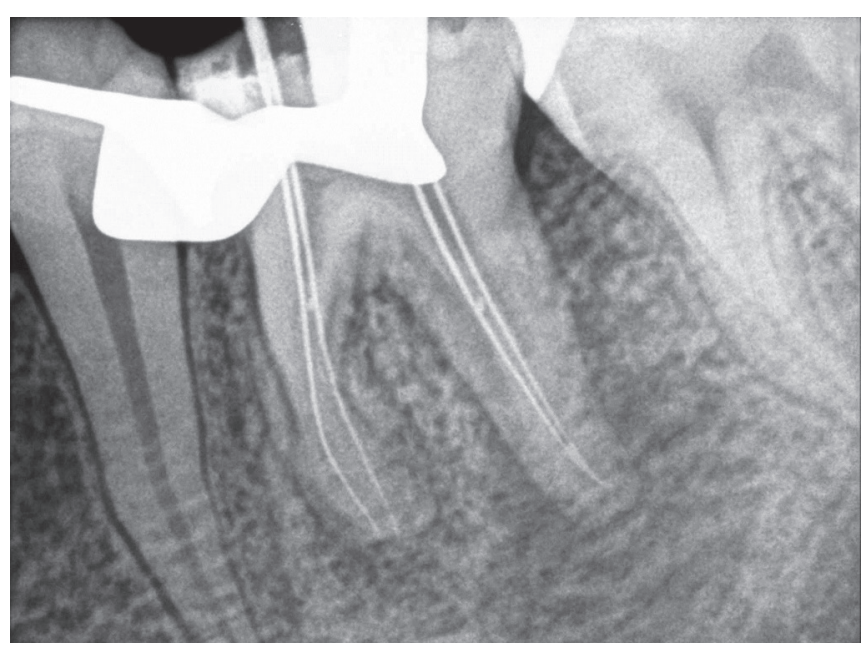

Fig. 3: Working length lopa
There was no decrease in size of sinus on 2 days recall with distal root of 46 (Fig. 4). Small incision was given on the most prominent part of swelling and drainage was established, hemostasis was achieved by application of pressure and topical application of antifibrinolytic agent (Tranexamic acid). Tranexamic acid is prepared in paste form by crushing the tablet of tranexamic acid (Tranexa ${ }^{\circledR}$ ) $500 \mathrm{mg}$ with distilled water to form a paste.

Next day, swelling reduced, so biomechanical preparation with 46 was completed and again closed intracanal calcium hydroxide dressing was given. The patient was recalled after 7 days.

Tooth was completely asymptomatic on 7 day recall without any swelling or pain, so obturation was completed with 46 (Figs 5 and 6). The patient will be followed clinically every 6 months to monitor periradicular responses.

\section{DISCUSSION}

Hemophilia is a hereditary disorder of coagulation results in deficiency of factor VIII (Hemophilia A) or factor IX

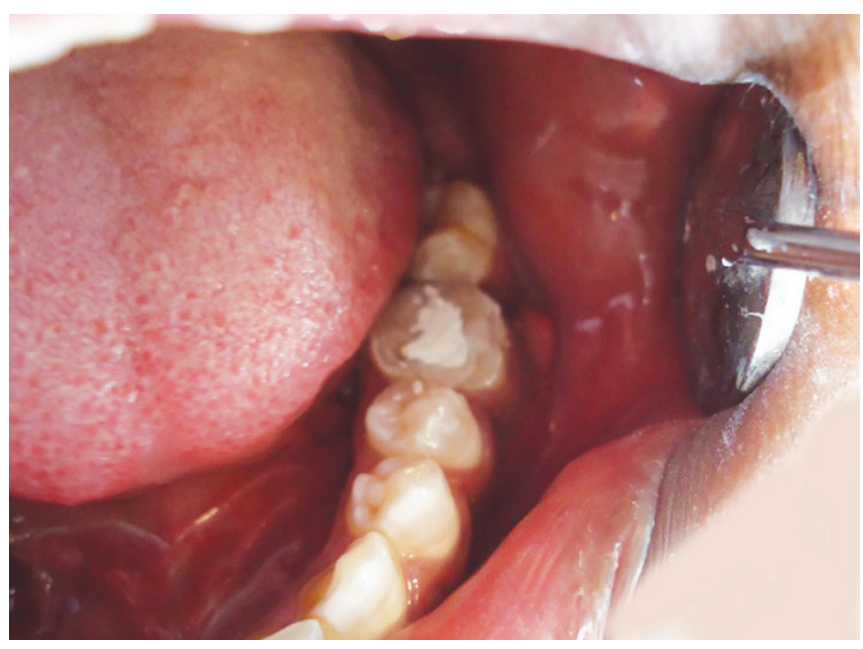

Fig. 4: Swelling after 2 day recall

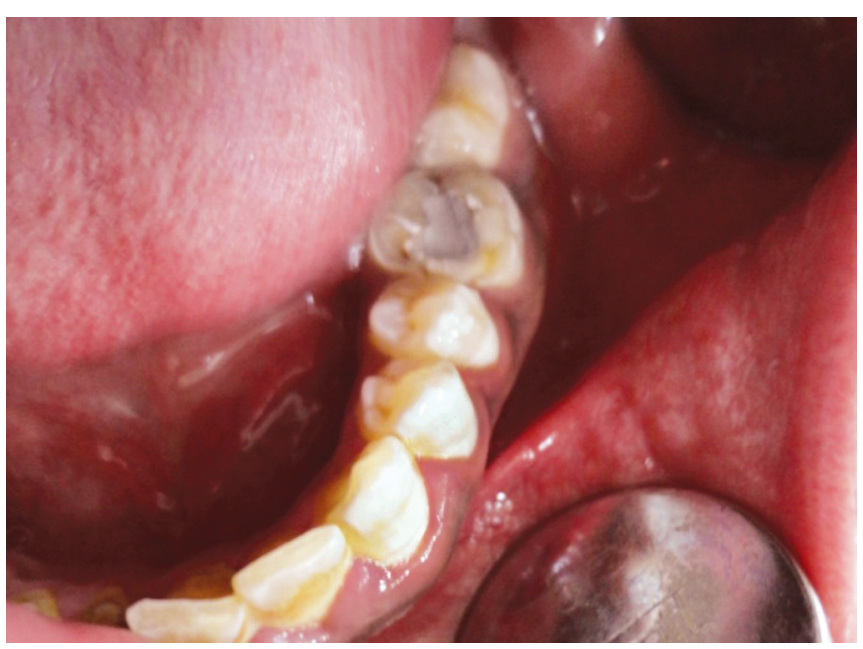

Fig. 5: After completion of root canal treatment 


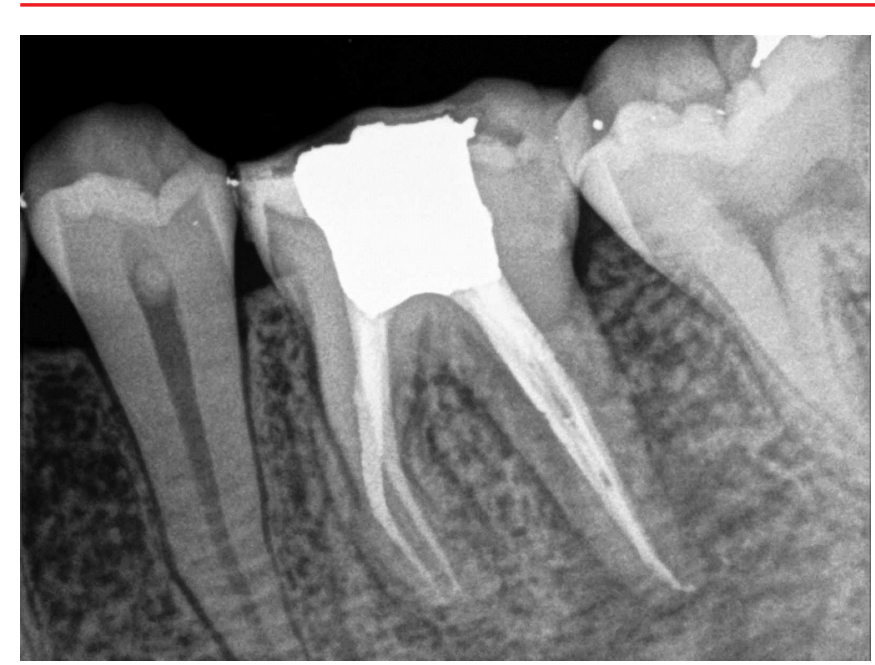

Fig. 6: Postoperative lopa

(hemophilia B). The disease is almost exclusively seen in males while females are asymptomatic carries. Rarely it can affect females. It can also be caused by mutation.

There is generally no contraindication for performing endodontic treatment for hemophilic patients. Pulpotomy and pulpectomy are preferable to extraction, but instrumentation and filling should never be done beyond the apical region of a vital tooth. Nonvital teeth should be treated at least 2 to $3 \mathrm{~mm}$ short of the radiographic apex..$^{5}$ The use of electronic endometric instruments will reduce the number of intraoperative radiographs and hence decreases chances of soft tissue injury.

In all but severe hemophiliac patients endodontic treatment can be usually carried out under antifibrinolytic cover (usually tranexamic acid, Tranexa ${ }^{\circledR}, 500 \mathrm{mg}$ ). It significantly reduces blood loss and can be given topically or systemically. ${ }^{6}$

Intracanal injection of LA solution containing adrenaline or topical application (using paper points) of adrenaline 1:100000 may be useful to minimize bleeding. ${ }^{8}$ The bleeding tendency can be aggravated by NSAIDs and hence safer alternatives for pain control are acetaminophen, codeine and Cox-2 inhibitors. Local anesthetic regional blocks, lingual infiltrations or injections into the floor of the mouth must not be used in the absence of Factor VIII replacement because of the risk of hemorrhage hazarding the airway that might be life-threatening. ${ }^{8}$ Rubber dam usage is extremely helpful during which notches may be placed in buccal and lingual surfaces of the tooth with a fissure bur in to which clamp prongs will fit tightly to avoid accidental displacement of clamp and subsequent soft tissue injury. ${ }^{7}$

There are no basic differences in the oral health problems of the hemophiliac and those of the average individual; however, optimal dental health is more of a necessity for the hemophiliac in view of the problems posed by dental surgery. Therefore, it is reasonable to expect that today's dental health professionals can and should provide the care so desperately needed by the hemophiliacs. ${ }^{9}$

\section{CONCLUSION}

It is concluded that, with sufficient precautions and effective protocols, based on the merits of a case, endodontic treatment can be performed without major concerns in hemophilic patients. Early dental care is of prime importance in such patients to avoid invasive procedures at a future date. A thorough understanding of the problems, especially hemophilia helps the dental professional to perform a systematic evaluation and anticipate potential hazards rather than being caught unawares with inadequate and desperate local hemostatic measures.

\section{REFERENCES}

1. Available at: at//www.hemophilia.ca/en/pdf/13/GFFchap1.pdf. Assessed on 12 April 2012.

2. Available from: http:// en.wikipedia.org/wiki/Grigori_Rasputin. Assessed on 12 April 2012.

3. Israels S, Schwetz N, Boyar R, McNicol A. Bleeding disorders: Characterization, dental considerations and managements. J Can Dent Assoc 2006;72:827.

4. White GC 2nd, Rosendaal F, Aledort LM, Lusher JM, Rothschild C, Ingerslev J. Factor VIII and Factor IX Subcommittee. Definitions in hemophilia. Recommendation of the scientific subcommittee on factor VIII and factor IX of the scientific and standardization committee of the International Society on Thrombosis and Haemostasis. Thromb Haemost 2001; 85(3):560.

5. Chohayeb A. Endodontic therapy in the hemophiliac patient. NY State Dent J 1981;47:326-327.

6. Borea G, Montebugnoli L, Capuzzi P, Magelli C. Tranexamic acid as a mouthwash in anticoagulant-treated patients undergoing oral surgery. An alternative method to discontinuing anticoagulant therapy. Oral Surg Oral Med Oral Pathol 1993; 75:29-31

7. Evans BE, Aledort LM. Hemophilia and dental treatment. J Am Dent Assoc 1978;96:827-834.

8. Kumar NJ, Kumar A, Varadarajan, Sharma N. Endodontics for the haemophiliac, a multidisciplinary perspective. JCD 2007;10(2):59-63.

9. Snyder DT, Penner JA. Preventive and restorative dental care for the hemophiliac. J Mich State Dent Assoc 1970;52:6-8.

\section{ABOUT THE AUTHORS}

\section{Rahul Ramesh Atara}

Lecturer, Department of Conservative, VSPM Dental College and Research Center, Dentistry and Endodontics, Maharashtra, India 


\section{Pratima Ramakrishna Shenoi}

Head, Department of Conservative Dentistry and Endodontics, VSPM Dental College and Research Center, Nagpur, Maharashtra, India

\section{Wanmala Ramchandra Mute}

Professor, Department of Conservative Dentistry and Endodontics, VSPM Dental College and Research Center, Nagpur Maharashtra, India

\section{Chetana Sachin Makade}

Associate Professor, Department of Conservative Dentistry and Endodontics, VSPM Dental College and Research Center, Nagpur Maharashtra, India

\section{Anup Kiran Mahajan (Corresponding Author)}

Junior Resident III, Department of Conservative Dentistry and Endodontics VSPM Dental College and Research Center, Nagpur, Maharashtra India, Phone: 8888858316, e-mail: anupkmahajan@gmail.com 